\title{
Breast Cancer Death Rates* Among Women Aged 50-74 Years, by Race/ Ethnicity — National Vital Statistics System, United States, 2006 and 2016
}

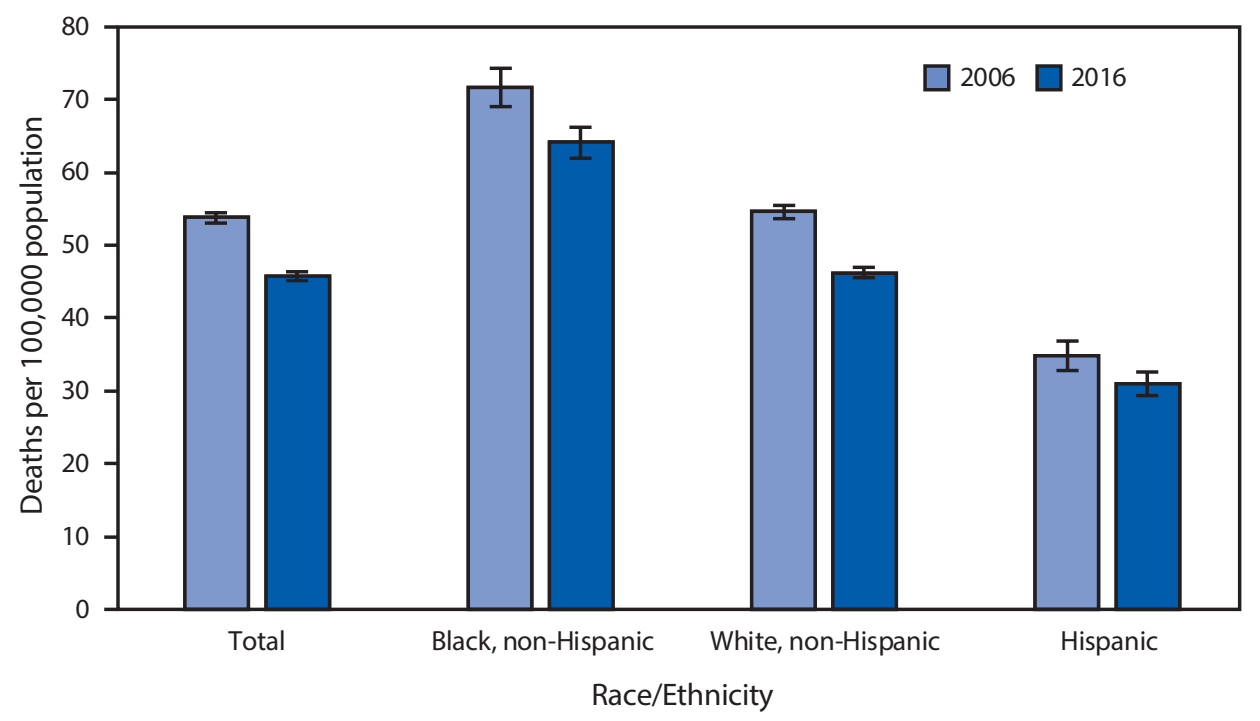

* Breast cancer deaths were those with International Classification of Diseases, Tenth Revision underlying cause of death code $\mathrm{C} 50$.

The death rate from breast cancer among all women aged 50-74 years decreased $15.1 \%$, from 53.8 per 100,000 in 2006 to 45.7 in 2016. In both 2006 and 2016, the death rate was higher among non-Hispanic black women compared with non-Hispanic white women and Hispanic women. From 2006 to 2016, the death rate from breast cancer decreased for non-Hispanic white women from 54.6 per 100,000 to 46.2, for Hispanic women from 34.8 to 31.0, and for non-Hispanic black women from 71.7 to 64.1.

Source: National Vital Statistics System, 2006 and 2016. https://wonder.cdc.gov/ucd-icd10.html.

Reported by: Sibeso N. Joyner, MPH, sjoyner@cdc.gov, 301-458-4254; Deepthi Kandi, MS. 